\title{
The Serological Differentiation of Staphylococcal Bacteriophages
}

\author{
BY PHYLLIS M. ROUNTREE* \\ Staphylococcal Reference Laboratory, Central Public Health Laboratory, \\ Colindale, London
}

SUMMARY : By the use of anti-bacteriophage sera prepared in rabbits, thirty-nine staphylococcal phages were divided into six serological groups. The first group (A) comprised phages lysing coagulase-positive staphylococci of human origin. They were stable at $20^{\circ}$ but inactivated at $49^{\circ}$. They multiplied in broth cultures containing sufficient tryptophan but rarely produced clearing of such cultures. The second group (B) lysed both bovine and human coagulase-positive staphylococci. They were markedly sensitive to heat and required growth factors present in the vitamin B complex. Group $\mathbf{C}$ comprised phages of ovine origin which were antigenically related to group $B$ phages and also resembled them in their growth requirements. Group $\mathbf{D}$ comprised phage $\mathbf{K}$, which lysed both coagulase-positive and negative staphylococci and was antigenically related only to phage $W$. Phage $W$ belonged to group $\mathrm{E}$ and lysed only some coagulase-negative staphylococci. Group $\mathrm{F}$ was related in its general characters with the phages of group $A$.

A staphylococcus was found carrying two serologically distinct phages, one of which was detected during the process of adaptation of a phage filtrate to a new propagating strain.

Since many strains of staphylococci are lysogenic, lytic filtrates may contain contaminating phages which manifest themselves during adaptation. Adequate serological characterization of the phages used for typing and for investigations of phage-bacterium relationships and of apparent mutation is therefore necessary.

Antisera to bacteriophages have been a valuable tool for the definition of the relationships of various races of phages (Burnet, 1933; Craigie, 1940). The only serological investigation of staphylococcal phages is that of Burnet \& Lush (1935) who examined a series of thirteen staphylococcal phages and by serological and other methods distinguished six groups among them. Since the introduction by Wilson \& Atkinson (1945) of their method of phage-typing staphylococci, a larger series of phages has become available for examination. This communication deals with the serological examination of these phages. In the series there has also been included a number of other staphylococcal phages whose reactions are of interest. The results indicate that the serological characteristics of the phages are associated with other properties such as stability and the range of organisms lysed.

\section{MATERIAL AND METHODS}

The bacteriophages. The bacteriophages used were as follows.

(a) The series originally described by Wilson \& Atkinson for the typing of staphylococci of human origin. Their nomenclature has since been simplified by omitting the designation of the propagating strain of staphylococcus, and,

* Permanent address: Fairfax Institute of Pathology, Royal Prince Alfred Hospital, Sydney, Australia. 
in cases where phages were developed by adaptation, by giving to the adapted phage the number of the original phage plus a suitable letter; e.g. 3/211 has become $3 \mathrm{~B}$ and $3 / 1339$ has become $3 \mathrm{C}$. A number of adapted phages has been added to the original collection.

(b) Three phages, X2, G12 and S7, lysing staphylococci pathogenic to sheep and isolated by Dr Williams Smith.

(c) The phage $\mathrm{K}$ of Kreuger \& Northrop (1930-1) is phage Au 2 in Burnet \& Lush's series. For an account of its history Burnet \& Lush's paper should be consulted. It is probable that this is the polyvalent phage used by a number of workers.

(d) Phages 21 and $\mathbf{W}$ isolated in Australia (Rountree, 1947 a,b).

(e) Eight phages obtained from cultures examined during an investigation of lysogenicity; phages 145/211, CK5/145, S17/211 and phage from strain 1339 propagated on five different strains.

Anti-bacteriophage sera. Sera were prepared in rabbits against phages 29, $51, W, X 2$ and 1339. The usual course of injections of the phage filtrates was $0 \cdot 5,0 \cdot 8,1 \cdot 0,1 \cdot 5$ and $2 \cdot 0 \mathrm{ml}$. at 5 -day intervals, the rabbits being bled $7-9$ days after the last injection. I am indebted to Dr Elford for a supply of anti-K serum and to Dr Williams Smith for a supply of anti-42 D serum.

Phage neutralization tests. These were carried out by the method of Burnet (1933). Dilutions of the sera, usually tenfold, were made in nutrient broth and an equal volume of diluted phage added to each tube. The phage dilution used was that which had been previously shown to give a countable number (50-200) of plaques when $0.02 \mathrm{ml}$. quantities were plated. The phage-serum mixtures were incubated at $37^{\circ}$ for $4 \mathrm{hr}$. and $0.02 \mathrm{ml}$. quantities plated in duplicate on the appropriate propagating strain of staphylococcus. After incubation overnight at $37^{\circ}$ the number of plaques was counted. The titre of the serum was expressed as the reciprocal of that dilution which gave approximately $80 \%$ reduction in the plaque count as compared with that given by controls consisting of phage diluted with normal rabbit serum or broth.

\section{RESULTS}

\section{Phage neutralization tests}

Titrated with their homologous phages, the serum titres were: 20,000 for $29,42 \mathrm{D}, 51$ and $1339 ; 10,000$ for X2; 100,000 for $\mathrm{K}$; and 200,000 for $\mathrm{W}$.

The neutralizing power of these sera was tested with thirty-nine staphylococcal phages (Table 1). Every phage was tested against serum 51, but when, during the course of the work, it became apparent that definite groups of phages could be distinguished which did not react with sera neutralizing other groups, only a few representative phages in each group were tested. The results show that it is possible to divide the phages into six serological groups, which for purposes of convenience have been designated $\mathrm{A}, \mathrm{B}, \mathrm{C}, \mathrm{D}, \mathrm{E}$ and $\mathrm{F}$.

Group A contains the phages $3 \mathrm{~A}, 3 \mathrm{~B}, 3 \mathrm{C}, 6,7,14,42 \mathrm{~B}, 42 \mathrm{E}, 47,47 \mathrm{~A}, 47 \mathrm{~B}$, $47 \mathrm{C}, 51$ and $\mathrm{R} 1760$. These are neutralized by serum 51 and not by the other sera. The serum titre is slightly lower $(10,000)$ against phages $42 \mathrm{E}, 47,47 \mathrm{~A}$ 
and $47 \mathrm{~B}$, indicating either minor antigenic differences or some variation in the degree of reactivity of these four phages. As a whole, however, the phages may be considered to form a serologically homogeneous group.

Group B contains phages 29, $29 \mathrm{~A}, 31,31 \mathrm{~A}, 44,44 \mathrm{~A}, 52,52 \mathrm{~A}, \mathrm{AH} 2941$, $42 \mathrm{C}$ and $42 \mathrm{D}$. They are neutralized by sera 29 and $42 \mathrm{D}$, and although the neutralization titres vary, the group as a whole is serologically differentiated. Sera against 29 and $42 \mathrm{D}$ were used as it was thought that they might reveal differences in these phages, since phage 29 was isolated from a staphylococcus

Table 1. The neutralization of staphylococcal bacteriophages by antiphage sera

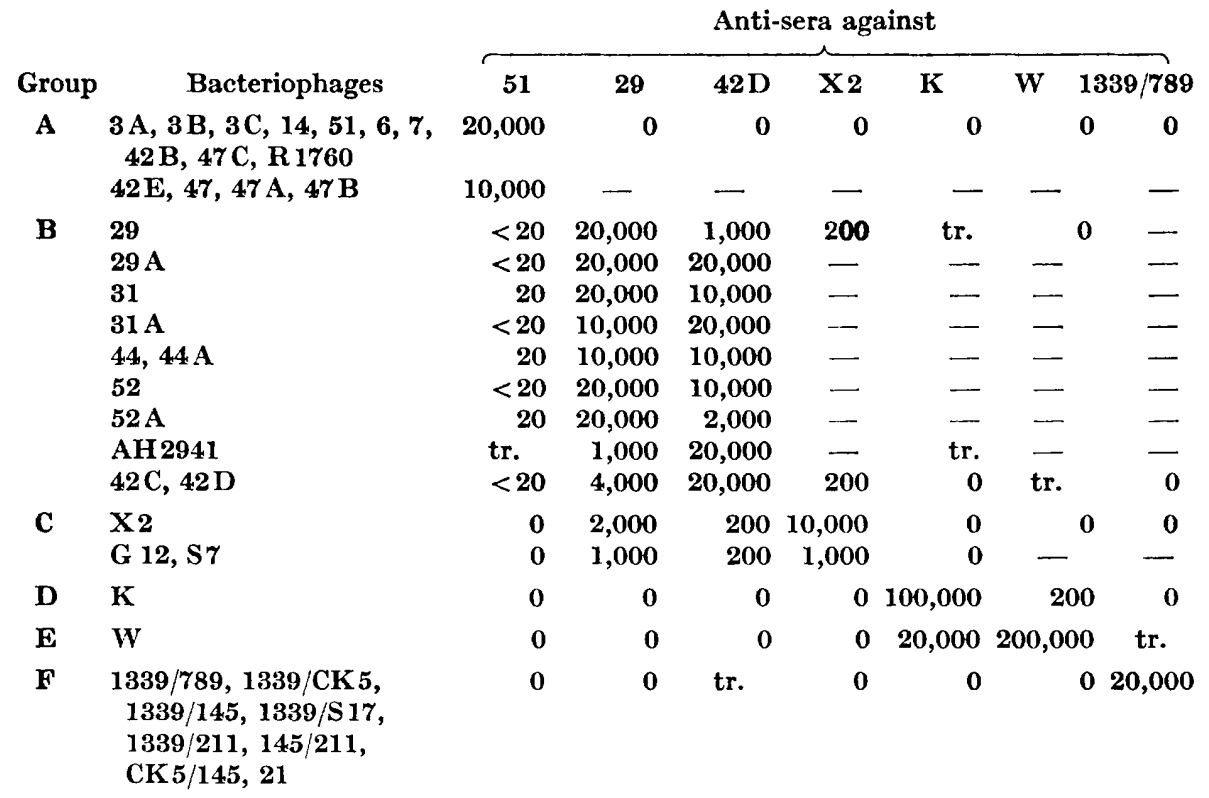

The results are expressed as the reciprocals of the serum dilutions neutralizing $80 \%$ of the phage; tr. indicates $<80 \%$ neutralization by a $1 / 2$ dilution of serum.

of human origin, whereas phage $42 \mathrm{D}$, although first propagated on a strain isolated from an outbreak of human staphylococcal food-poisoning, was found by Dr Williams Smith to lyse many strains from bovine mastitis. The results indicate that these two phages are not identical but are closely related. The phages in this group cross-reacted slightly with serum 51 and more markedly with serum X2. This overlap with $X_{2}$ is of interest in view of the animal origin of some of the strains lysed by $42 \mathrm{D}$ and the animal origin of phage $\mathbf{X} 2$.

Group $\mathrm{C}$ consists of the three ovine phages X2, G12 and S7. All three crossreact with sera 29 and $42 \mathrm{D}$ and appear to be fairly closely related antigenically to the phages of group B. The differences, however, are great enough to justify their separation as a distinct serological group. There are differences also between $\mathrm{X}_{2}$ and the other two phages G12 and S7 which indicate that they are not identical. 
Phage $\mathrm{K}$ is a serologically distinct phage and is assigned to a separate group D. It is of interest since it has such a wide range of activity against both coagulase-positive and negative staphylococci. The only phage to which it bears any appreciable relation is $W$, which lyses only some coagulase-negative staphylococci. Phage $\mathrm{W}$ is assigned to a separate group $\mathrm{E}$.

Phages $\mathrm{K}$ and $\mathbf{W}$ are obviously also distinct from all the other phages examined.

Group $F$ phages are neutralized by a serum prepared against phage 1339/789 and not by the other sera. No cross-reactions occurred between this serum and the phages of the other groups. The phages in this group were isolated from lysogenic coagulase-positive staphylococci of human origin. They resemble in many respects those of group $\mathbf{A}$. The phages which fall into this group are $1339 / 789,1339 /$ CK 5, 1339/145, 1339/S 17, 1339/211, 145/211, CK 5/145 and 21. None of these phages has been used in the routine typing of staphylococci. There remains one phage, S17/211, isolated from a lysogenic strain, which was not neutralized by any of the available sera.

\section{Diversity of serological characters of phages $42 B, 42 C, 42 D$ and $42 E$}

Table 1 shows that phages $42 \mathrm{~B}$ and $42 \mathrm{E}$ fall into serological group $\mathrm{A}$, whereas $42 \mathrm{C}$ and $42 \mathrm{D}$ belong to group $\mathrm{B}$. Since these phages were all developed by adaptation from a single, presumably pure phage, their history was accordingly re-examined. The original 42 filtrate was obtained by lysing a strain 34, with the phage carried by strain 36. Strain 34, however, also carried a phage which lysed 36 . Phage $42 \mathrm{~A}$ was derived from 42 by adaptation to strain 36 , i.e. it was $42 / 36$. Phage $42 \mathrm{~B}$ was phage 42 adapted to strain 1163 , and phage $42 \mathrm{E}$ was 42 adapted to strain 1670. However, $42 \mathrm{C}$ was derived from phage $42 \mathrm{~A}$ adapted to strain 1307, and was used for adaptation to strain 1363 , becoming $42 \mathrm{D}$.

Strains 34 and 36 were re-examined for lysogenicity by cross-testing on agar plates with the stock propagating staphylococci. Strain 34 was found to be lysogenic for strains $3,36,1670$ and R 1760, whereas strain 36 carried phage which lysed strains 3, 34, R 1760 and 1307 . Phages $36 / 3$ and 36/1307 were then isolated by picking single plaques and replating several times. Active filtrates of these phages were then tested against sera $42 \mathrm{D}$ and 51. Phage 36/3 was neutralized by serum 51 and not by serum $42 \mathrm{D}$, whereas the reverse was the case with phage 36/1307. It is apparent, therefore, that in the process of lysis of staphylococcus 36 by phage $42 \mathrm{~A}$ the phage carried by 36 and active against 1307 had also been set free. This phage was present in small numbers in the filtrate $42 \mathrm{~A}$. When the undiluted filtrate was added to strain 1307 during the process of adaptation, the plaques developing on 1307 were due to this phage. It follows that phage $42 \mathrm{C}$ is not a true adapted phage and is unrelated to phages $42 \mathrm{~B}$ and $42 \mathrm{E}$. It is also of interest that the staphylococcus strain 36 carries two phages which are antigenically distinct.

Phages 42 and 42 A have been discarded from the collection, but phage 47 is apparently similar to them and is propagated on strain 36 . The stock 
preparation of 47 gave a phage count of $210,000,000$ particles $/ \mathrm{ml}$. when plated on 36 , and of 1000 particles $/ \mathrm{ml}$. when plated on 1307 , a ratio of $1: 210,000$. This ratio might be considered, in the absence of serological examination of the phages, as evidence of mutation, but is, in fact, due to the contamination of the 47/36 filtrate with phage derived from 36 . Since a large proportion of staphylococci are known to be lysogenic, it follows that in some cases apparent adaptation of phages may be due solely to the manifestation of contaminating phages derived from the propagating staphylococci.

\section{Correlation of serological groups with other characters of the phages}

Some of the characters of the phages and of the staphylococci which they lyse are set out in Table 2.

Range of staphylococci lysed. Group A phages lyse only coagulase-positive staphylococci of human origin, whereas those of group B, although lysing only coagulase-positive cocci, attack both human and bovine strains. The group

Table 2. The characters of the six serological groups of staphylococcal bacteriophages and of the range of staphylococci which they lyse

\begin{tabular}{|c|c|c|c|c|c|c|c|c|}
\hline & & Char & acters of $b$ & bacterioph & & & & \\
\hline & Mult & $\begin{array}{l}\text { iplication } \\
37^{\circ}\end{array}$ & & & Range of & & $\begin{array}{l}\text { aracters of } \\
\text { staphylo }\end{array}$ & $\begin{array}{l}\text { susceptible } \\
\text { cocci }\end{array}$ \\
\hline $\begin{array}{c}\text { Serologic } \\
\text { group }\end{array}$ & $\begin{array}{r}\text { cal On } \\
\text { agar }\end{array}$ & $\begin{array}{l}\text { In Todd- } \\
\text { Hewitt } \\
\text { broth }\end{array}$ & $\begin{array}{l}\text { Stability } \\
\text { at } 4^{\circ}\end{array}$ & $\begin{array}{l}\text { Inactivation } \\
\text { in } 1 \mathrm{hr} . \\
\text { at } 49^{\circ}\end{array}$ & $\begin{array}{l}\text { plaque } \\
\text { size } \\
(\mathrm{mm} .)\end{array}$ & Origin & Coagulase & $\begin{array}{c}\text { Phage } \\
\text { inactivating } \\
\text { agent }\end{array}$ \\
\hline $\mathbf{A}$ & + & + & + & + & $0 \cdot 3-0 \cdot 7$ & Human & + & Nucleo-protein \\
\hline $\mathbf{B}$ & + & - & - & + & $0 \cdot 3-1 \cdot 2$ & $\begin{array}{r}\text { Human, } \\
\text { bovine }\end{array}$ & + & \\
\hline C & + & - & \pm & $\begin{array}{l}\text { X2- } \\
\text { S7 partial } \\
\text { G12 }\end{array}$ & $0 \cdot 7-1 \cdot 0$ & Ovine & + & \\
\hline $\mathbf{D}$ & + & + & + & Partial & 0.5 & $\begin{array}{l}\text { Human, } \\
\text { animal }\end{array}$ & and - & Polysaccharide \\
\hline $\mathbf{F}$ & + & + & + & - & $0 \cdot 6$ & Human & - & \\
\hline $\mathbf{F}$ & + & - & + & + & 0.5 & Human & + & \\
\hline
\end{tabular}

C phages are of ovine origin, and their antigenic overlap with the group $B$ phages has already been mentioned. Phage $\mathbf{K}$, which lyses both coagulasepositive and negative staphylococci has an antigenic relationship only with phage $W$, which lyses about $30 \%$ of the coagulase-negative staphylococci tested. There therefore appears to be a clear-cut relationship between the serological characters of the phages, their origins, and certain of the characters of the staphylococci sensitive to them.

Plaque size. The staphylococcal phages produce relatively small plaques on agar. Plaque size varies inversely with the concentration of agar in the medium. Brands of agar vary considerably in the consistency of the gels they produce. For example, with powdered agar of New Zealand origin, a concentration of $0.8 \%$ gives a gel of consistency comparable to that of the $1.25 \%$ shredded Japanese agar used in many laboratories in the past. The shred agar 
proved superior to the powdered agar which, in the concentration giving maximum plaque size, has a tendency to slip around in plates and is therefore more difficult to manipulate. Provided that attention is paid to the brand of agar used and it is employed in a suitable concentration, measurements of plaque size should be replicable on a standard medium.

In the present investigation a medium containing $\mathbf{1 . 2 5} \%$ of shredded agar was used, with added peptone, Yeastrel and Fildes's peptic digest of blood; and the plaques grown overnight at $37^{\circ}$. This medium was developed in the Staphylococcal Reference Laboratory to provide satisfactory conditions for the maximum development of plaque size.

For any given phage there is a fairly wide range of plaque size, and 20-50 plaques were measured to obtain a mean plaque size. Among group A phages it varied from 0.33 to $0.7 \mathrm{~mm}$., the range of individual diameters being $0.1-1.0 \mathrm{~mm}$. The group A phages are as a whole less variable than the group B phages. Among the group B phages there are some which produce plaques up to $1.7 \mathrm{~mm}$. in diameter (phage 44). Though mean plaque sizes range from $\mathbf{0 . 3}$ to $\mathbf{1 . 2} \mathrm{mm}$., the group B phages tend to produce larger plaques than any other group except group $\mathrm{C}$, the ovine phages which produce plaques up to $\mathbf{1 . 3} \mathrm{mm}$. in diameter. X2 plaques are characteristic, being large and overgrown by secondary bacterial growth, giving a hazy appearance after overnight incubation. The phages $\mathrm{K}, \mathrm{W}$ and $\mathbf{2 1}$ produce moderately sized plaques with no particular distinguishing characteristics.

Table 3 gives the range of plaque sizes and the mean plaque sizes in $\mathrm{mm}$. for the majority of the phages, and illustrates the variation in plaque size.

Growth requirements. Many staphylococcal phages are difficult to grow in broth cultures (Burnet \& Lush, 1935; Fisk, 1942). Certain of Burnet \& Lush's phages grew only on agar at $22^{\circ}$ and not at $37^{\circ}$. Phage $\mathrm{K}$ is an outstanding exception in that it regularly clears broth cultures. In contrast to Burnet $\&$ Lush's 'weak' phages, all the phages used in this investigation produce plaques at $37^{\circ}$ on agar cultures containing Fildes's peptic digest of blood and Yeastrel, although irregular results were obtained in broth cultures. An explanation of these irregular results must be sought in the action of some factor other than temperature.

An attempt was made to estimate the time of the first release of phage from infected cells in Todd-Hewitt broth (1932). To $0.9 \mathrm{ml}$. quantities of broth placed in tubes in a water-bath at $37^{\circ}, 0.04 \mathrm{ml}$. of a young broth culture of the appropriate staphylococcus was added, followed by $0.1 \mathrm{ml}$. of phage so diluted in broth that a $0.02 \mathrm{ml}$. quantity of the final mixture on plating would give 10-20 plaques. Samples of $0.02 \mathrm{ml}$. were plated at the moment of mixing and at intervals up to $2 \mathrm{hr}$.; a sudden increase in the phage titre indicated that lysis of infected cells had occurred.

Phages $\mathbf{K}$ and $\mathbf{W}$ grew in these conditions, and after overnight incubation cleared the cultures. Among the group A phages, 3A, 3B, 3C, 14 and 51 multiplied in these conditions, the first release of phage taking place in 55-70 min. This generation time is long compared with that of Bact. coli phages or of staphylococcal phage with a generation time of $35 \mathrm{~min}$. 
The average burst size for phage 51 was found to be 35 . Taking into account the long latent period and the relatively small number of phage particles released from each infected cell it is obvious why complete clearing of broth cultures infected with these phages is rarely seen; the growth of the staphylococcus quickly outstrips that of the phage unless the dose of added phage is a large one.

Table 3. Plaque sizes of staphylococcal phages

\begin{tabular}{|c|c|c|c|}
\hline Group & Phage & Range & Mean \\
\hline $\mathbf{A}$ & $\begin{array}{c}3 \mathrm{~B} \\
3 \mathrm{C} \\
14 \\
51 \\
6 \\
7 \\
47 \\
47 \mathrm{~A}\end{array}$ & $\begin{array}{l}0 \cdot 1-0.9 \\
0.2-0 \cdot 6 \\
0.2-1 \cdot 0 \\
3 \cdot 1-0 \cdot 6 \\
0 \cdot 2-0 \cdot 6 \\
0 \cdot 1-0 \cdot 6 \\
0 \cdot 1-0 \cdot 7 \\
0 \cdot 4-0.8\end{array}$ & $\begin{array}{l}0 \cdot 6 \\
0 \cdot 4 \\
0 \cdot 7 \\
0 \cdot 4 \\
0 \cdot 35 \\
0 \cdot 33 \\
0 \cdot 43 \\
0 \cdot 58\end{array}$ \\
\hline B & $\begin{array}{l}29 \\
29 \mathrm{~A} \\
31 \\
31 \mathrm{~A} \\
42 \mathrm{C} \\
42 \mathrm{D} \\
44 \\
44 \mathrm{~A} \\
52 \\
52 \mathrm{~A}\end{array}$ & $\begin{array}{l}0 \cdot 3-1 \cdot 0 \\
0 \cdot 1-0 \cdot 8 \\
0 \cdot 2-1 \cdot 0 \\
0 \cdot 1-0 \cdot 6 \\
0 \cdot 5-1 \cdot 2 \\
0 \cdot 1-0 \cdot 8 \\
0 \cdot 8-1 \cdot 7 \\
0 \cdot 5-0 \cdot 9 \\
0 \cdot 5-1 \cdot 4 \\
1 \cdot 0-1 \cdot 5\end{array}$ & $\begin{array}{l}0 \cdot 68 \\
0 \cdot 5 \\
0 \cdot 7 \\
0 \cdot 3 \\
0 \cdot 8 \\
0 \cdot 38 \\
1 \cdot 2 \\
0 \cdot 6 \\
1 \cdot 0 \\
1 \cdot 2\end{array}$ \\
\hline $\mathrm{C}$ & $\begin{array}{l}\text { X2 } \\
\text { G12 } \\
\text { S7 }\end{array}$ & $\begin{array}{l}0 \cdot 7-1 \cdot 3 \\
0 \cdot 3-1 \cdot 0 \\
0 \cdot 3-1 \cdot 2\end{array}$ & $\begin{array}{l}1 \cdot 0 \\
0.76 \\
0 \cdot 68\end{array}$ \\
\hline D & $\mathbf{K}$ & $0 \cdot 3-0 \cdot 7$ & 0.5 \\
\hline $\mathbf{E}$ & $\mathbf{W}$ & $0.4-0.7$ & 0.62 \\
\hline $\mathbf{F}$ & 21 & $0.2-0.7$ & $0 \cdot 46$ \\
\hline
\end{tabular}

The results with the other group A phages in Todd-Hewitt broth were equivocal. In some cases a rise in phage count occurred after 100-110 min. incubation, but no clear-cut evidence of bursts could be obtained. However, on the addition of $\mathbf{0 . 0 0 2} \mathrm{mg} . / \mathrm{ml}$. tryptophan to the broth these phages reproduced in a normal manner.

No evidence of multiplication of group $B$ and group $C$ phages could be obtained. Indeed, in certain cases, notably $29,42 \mathrm{D}, \mathrm{X} 2, \mathrm{G} 12$ and $\mathrm{S} 7$, at the end of an hour's incubation very little of the added phage could be demonstrated on subculture. The inactivation of phages $\mathrm{X} 2, \mathrm{G} 12$ and $\mathrm{S} 7$ is almost complete under these conditions (Table 4). With the remainder of the group $\mathrm{B}$ phages and phage 21 , there was a loss of 50-80\% of phage. That this phage inactivation was not due to the temperature of incubation was shown by the fact that no inactivation occurred in broth containing no bacteria.

Work in progress with the group B and group $\mathrm{C}$ phages indicates that they require the addition to the broth of factors present in the vitamin $\mathbf{B}$ complex 
and of unknown factors that are removed from the broth during its sterilization by heat. The present interest lies in the fact that the variability in growth requirements is associated with serological character.

Table 4. Inactivation of ovine staphylococcal bacteriophages on incubation at $37^{\circ}$ in Todd-Hervitt broth cultures of their propagating strains

\begin{tabular}{crcc} 
& \multicolumn{3}{c}{ Phage count $/ \mathrm{ml}}$. \\
Time (min.) & $\mathbf{X 2}$ & $\mathbf{G 1 2}$ & $\mathrm{S7}$ \\
$\mathbf{0}$ & $\mathbf{4 , 0 0 0}$ & $\mathbf{3 0 , 0 0 0}$ & $\mathbf{3 , 1 0 0}$ \\
$\mathbf{3 0}$ & $\mathbf{6 0 0}$ & - & - \\
60 & 100 & $\mathbf{2 0 0}$ & $<50$ \\
70 & $\mathbf{1 0 0}$ & $\mathbf{1 0 0}$ & $<50$ \\
80 & 100 & $\mathbf{5 0}$ & $<\mathbf{5 0}$ \\
90 & $\mathbf{5 0}$ & $<50$ & $<\mathbf{5 0}$ \\
100 & $\mathbf{5 0}$ & $<50$ & $<50$ \\
120 & $<50$ & 50 & $<50$
\end{tabular}

Table 5. Inactivation of staphylococcal bacteriophages after heating for $1 \mathrm{hr}$. at $49^{\circ}$. The results are expressed as percentages of phage particles surviving

\begin{tabular}{lc}
\multicolumn{1}{c}{ Bacteriophages } & $\%$ surviving \\
$6,7,21,42 \mathrm{D}, 47,47 \mathrm{~A}, \mathrm{G} 12$ & 0 \\
$\mathbf{1 4}, \mathbf{2 9}, \mathbf{5 1}$ & $1-5$ \\
$3 \mathrm{~A}, 3 \mathrm{~B}, 3 \mathrm{C}, \mathrm{K}$ & $\mathbf{2 0 - 3 0}$ \\
S7 & 50 \\
X2, W & $90-100$
\end{tabular}

Stability. It had already been found by Dr V. D. Allison (personal communication) that certain of the phages used for typing could be maintained in the refrigerator for long periods of time without any loss of activity, while others showed a marked fall in titre on testing a few weeks after preparation. But during the transport of phage filtrates from England to Australia, by air in a refrigerator, certain of the phages became inactive. These unstable phages proved to be groups $\mathrm{B}$ and $\mathbf{C}$. Groups $\mathbf{A}$ and $\mathbf{F}$ phages and phages $\mathbf{K}$ and W were, on the contrary, remarkably stable.

This instability of group B phages may be an expression of their general sensitivity to a variety of agents. Thus phage $42 \mathrm{D}$ lost $95 \%$ activity after $90 \mathrm{~min}$. at $37^{\circ}$ in quarter-strength Ringer's solution. Such inactivation did not occur when the phage was incubated in broth or normal serum. Other phages in group B were not so markedly unstable. Nevertheless this instability makes it necessary constantly to check group B phages used for typing.

Effect of temperature. The instability of the group B and C phages made it of interest to determine the temperature of inactivation in all the serological groups. An exposure of $60 \mathrm{~min}$. in a water-bath at $49^{\circ}$ was chosen. The phages were so diluted in broth that, on plating, countable numbers of plaques were obtained. Samples were plated out at 0 and $60 \mathrm{~min}$. (Table 5). With two exceptions, namely, phages $\mathrm{X} 2$ and $\mathrm{W}$, in which the survival rate was 90-100\%, inactivation of the phages occurred. Most of group A was devoid of activity 
after heating, but $20-30 \%$ of phages $3 \mathrm{~A}, \mathbf{3 B}$ and $3 \mathrm{C}$ were viable at the end of $1 \mathrm{hr}$. Phage $\mathrm{K}$ resembled phages $\mathbf{3 A}, \mathbf{3 B}$ and $\mathbf{3 C}$ in its behaviour. The different survival rates of the ovine phages reflect the differences between these three phages already indicated by the incomplete inactivation of $S 7$ and G12 by anti-X 2 serum.

One practical conclusion to be drawn from these observations is that heat treatment of lysates or of cultures of lysogenic staphylococci is of no value in freeing such material from staphylococci, since the phages are inactivated at lower temperatures than are the bacteria.

\section{DISCUSSION}

In a previous paper (Rountree, 1947b) it was reported that nucleoprotein fractions from coagulase-positive strains 145,3 and 373 inactivated phage 51. It should be noted that $\mathbf{1 4 5}$ is the propagating strain for phage 51, 3 for phage 6 and 373 for phage $44 \mathrm{~A}$, and that these phages belong to the serological groups $\mathbf{A}$ and $\mathbf{B}$. These results with phage 51 were in contrast to those obtained by Freeman (1937), who isolated from strains of staphylococci a polysaccharide which, in high dilutions, inactivated phage Au 2 of Burnet \& Lush's series. This phage is apparently similar to if not identical with phage $\mathrm{K}$ (serological group $\mathbf{D}$ ). The behaviour of phages $\mathbf{K}$ and 51 with regard to serology, range of organisms lysed and time of multiplication indicates clear-cut differences between these two phages. It is therefore reasonable to suppose that they may be absorbed by different components of the staphylococcal cell surface.

One consequence of the different serological behaviour of the various staphylococcal phages is the necessity of characterizing staphylococcal phages as completely as possible, whether they are to be used for phage typing of staphylococci or for observations on the fundamental problems of phagebacterium relationships. The necessity of using antigenically similar phages for the identification of Vi strains of Bact. typhosum has recently been stressed by Craigie \& Felix (1947). The occurrence as contaminants in stock filtrates of phages carried by the lysogenic staphylococci used in the propagation of the stock phages, adds additional weight to the necessity of serological examination of phages appearing during adaptation of phage from one strain of staphylococcus to another, and for caution in interpreting results of apparent phage mutation among the staphylococcal phages.

This work was carried out under a grant from the Australian National Health and Medical Research Council.

My thanks are due to Dr G. S. Wilson, Director of the Public Health Laboratory Service for permission to work in the Staphylococcal Reference Laboratory, and to Dr V. D. Allison for his kindness in placing at my disposal all the facilities of the Reference Laboratory and all his extensive knowledge of the phages. I would also wish to thank Mr G. Heimer for much valuable technical assistance. 


\section{REFERENCES}

Burnet, F. M. (1933). The classification of dysentery-coli bacteriophages. II. The serological classification of coli-dysentery phages. J. Path. Bact. 36, 307.

Burnet, F. M. \& Lusir, D. (1935). The staphylococcal bacteriophages. J. Path. Bact. 40, 455.

Craigie, J. (1940). Variation of type II Vi phage. Proc. 3rd Int. Congr. Microbiol. p. 296.

Craigie, J. \& Felix, A. (1947). Typing of typhoid bacilli with Vi bacteriophages; suggestions for its standardization. Lancet, i, 823.

FIsk, R. T. (1942). Studies on staphylococci. I. The occurrence of bacteriophage carriers among strains of S. aureus. J. infect. Dis. 71, 153.

Freeman, M. (1937). The phage-inactivating agent in extracts of S. aureus. Aust. J. exp. Biol. med. Sci. 15, 221.

Kreuger, A. P. \& Northrop, J. H. (1930-1). The kinetics of the bacteriumbacteriophage reaction. J. gen. Physiol. 14, 223.

Rountree, P. M. (1947 $a)$. Staphylococcal bacteriophages. I. The effect of penicillin on staphylococcal bacteriophages. Aust. J. exp. Biol. med. Sci. 25, 9.

Rountree, P. M. (1947b). Staphylococcal bacteriophages. II. Bacteriophage absorption by staphylococci. Aust. J. exp. Biol. med. Sci. 25, 203.

Todd, E. W. \& Hewitr, L. F. (1932). A new culture medium for the production of antigenic streptococcal haemolysin. J. Path. Bact. 32, 973.

Wilson, G. S. \& Atrinson, J. D. (1945). Typing of staphylococci by the bacteriophage method. Lancet, i, 647. 